\title{
Fibroblast growth factor 21 enhances cholesterol efflux in THP-1 macrophage-derived foam cells
}

\author{
WEI SHANG ${ }^{1 *}$, XUEJING YU $^{1 *}$, HONGLIAN WANG ${ }^{2}$, TIELIN CHEN ${ }^{2}$, YING FANG $^{2}$, \\ XIANGGUI YANG ${ }^{3}$, PUHUI ZHOU ${ }^{3}$, FANG NIE ${ }^{3}$, QIN ZHOU ${ }^{2,3}$ and JIANZHONG ZHOU ${ }^{1}$ \\ ${ }^{1}$ Department of Cardiology, The First Affiliated Hospital, Chongqing Medical University, Chongqing 400016; \\ ${ }^{2}$ Core Facility of Genetically Engineered Mice, State Key Laboratory of Biotherapy and Cancer Center, West China Hospital, \\ Sichuan University, Chengdu, Sichuan 610041; ${ }^{3}$ The Division of Molecular Nephrology, The College of Laboratory Medicine, \\ Chongqing Medical University, Chongqing 400016, P.R. China
}

Received October 5, 2013; Accepted April 25, 2014

DOI: $10.3892 / \mathrm{mmr} .2014 .2731$

\begin{abstract}
Fibroblast growth factor 21 (FGF21) is a novel metabolic regulator. The present study aimed to investigate the effect of FGF21 on cholesterol efflux and the expression of ATP binding cassette (ABC) A1 and G1 in human THP-1 macrophage-derived foam cells. Furthermore, the present study aimed to investigate the role of the liver $\mathrm{X}$ receptor (LXR) $\alpha$ in this process. A model of oxidized low-density lipoprotein-induced foam cells from human THP-1 cells was established. The effect of FGF21 on cholesterol efflux was analyzed using a liquid scintillation counter. The expression of ABCA1 and ABCG1 was determined using quantitative polymerase chain reaction and western blot analyses. FGF21 was found to enhance apolipoprotein A1- and high-density lipoprotein-mediated cholesterol efflux. FGF21 was also observed to increase the mRNA and protein expression of ABCA1 and ABCG1. Furthermore, LXR $\alpha$-short interfering RNA attenuated the stimulatory effects induced by FGF21. These findings suggest that FGF21 may have a protective effect against atherosclerosis by enhancing cholesterol efflux through the induction of LXR $\alpha$-dependent ABCA1 and ABCG1 expression.
\end{abstract}

\section{Introduction}

Atherosclerosis, one of the leading causes of morbidity and mortality worldwide, is a chronic inflammatory disease and a disorder of lipid metabolism (1). The accumulation of excess

Correspondence to: Professor Jianzhong Zhou, Department of Cardiology, The First Affiliated Hospital, Chongqing Medical University, 1 You Yi Road, Yu Zhong, Chongqing 400016, P.R. China E-mail: zhoujianzhong163@163.com

\section{${ }^{*}$ Contributed equally}

Key words: fibroblast growth factor 21 , liver $\mathrm{X}$ receptor $\alpha$, ATP binding casette A1, ATP binding casette G1, cholesterol efflux, atherosclerosis cholesterol has been recognized as a crucial event in the development of atherosclerosis (2); therefore, preventing or reversing cholesterol accumulation may be effective protective strategies against atherosclerosis. A growing body of evidence suggests that high density lipoprotein (HDL) has an important role in the removal of cholesterol from atherosclerotic plaques and the transport of the excess cholesterol back to the liver for its subsequent elimination as bile acids and neutral steroids. This process is termed reverse cholesterol transport (RCT) and is one of the major protective mechanisms against the development of atherosclerosis (3-5).

Cholesterol efflux from macrophage-derived foam cells is an initial and key step in RCT (6), and serves as an integrated measure of HDL quantity and quality (7). This cholesterol efflux involves numerous genes, including ATP-binding cassette (ABC) A1 and G1 (8). ABCA1 is a member of the $\mathrm{ABC}$ superfamily and is the defective gene in Tangier disease. ABCA1 has been reported to have an important role in the prevention of atherosclerosis through facilitating cholesterol efflux from macrophages to lipid-poor apolipoproteinA-I (apoA-I), and decreasing cholesterol accumulation in macrophages (9). Similar to ABCA1, ABCG1 is capable of promoting cholesterol efflux from macrophages to mature HDL particles, but not to apoA-I (10).

Liver $\mathrm{X}$ receptor $(\mathrm{LXR}) \alpha$, a member of the nuclear hormone receptor superfamily, has a crucial role in cholesterol metabolism (11). Upon activation, LXR $\alpha$ induces numerous genes, which are involved in cholesterol efflux, absorption, transport and excretion. ABCA1 and ABCG1 have been identified as direct targets of $\operatorname{LXR} \alpha(12)$.

Fibroblast growth factor (FGF) 21 is a member of the FGF superfamily and is predominantly secreted by the liver and adipose tissue. FGF21 has gained attention for its multiple metabolic functions (13). FGF21 was first identified to stimulate glucose uptake in mouse 3T3-L1 adipocytes, which was observed to be additive and independent of insulin (14). FGF21 has also been shown to improve function and survival of pancreatic $\beta$-cells (15) and to decrease glucagon secretion (16), which together enhance insulin sensitivity. In addition, FGF21 has been found to increase energy expenditure in mice with free access to food (17) and promote weight loss in diabetic 
primates (18). Furthermore, FGF21 exerts favorable effects on lipid metabolism in animal models. FGF21 administration has been found to reduce the levels of plasma triglycerides (TGs), free fatty acids (FFAs) and cholesterol in genetically compromised diabetic and obese rodents (19). Moreover, in diabetic monkeys, FGF21 treatment has been shown to reduce the levels of TG and LDL and increase those of HDL (20). The therapeutic role of recombinant human FGF21 in type 2 diabetes and dyslipidemia is under investigation. The disruption of glucose and lipid metabolism are important processes in the pathogenesis of atherosclerosis, and FGF21 has numerous benefits on glucose and lipid metabolism. Therefore, FGF21 may represent a promising therapeutic hormone for the treatment of atherosclerosis.

The present study investigated the effect of FGF21 on cholesterol efflux, and ABCA1 and ABCG1 mRNA and protein expression in oxidized low-density lipoprotein (ox-LDL)-stimulated macrophage foam cells. The mechanism by which FGF21 induces these effects was also investigated.

\section{Materials and methods}

Materials. Recombinant Human FGF-21 was obtained from Shanghai Jinan Co., Ltd. (Shanghai, China). Phorbol-12-myristate-13-acetate (PMA), bovine serum albumin (BSA) and horseradish peroxidase (HRP)-conjugated anti-rabbit secondary antibodies were purchased from Sigma-Aldrich (St. Louis, MO, USA). Fetal bovine serum (FBS) was purchased from Gibco-BRL (Carlsbad, CA, USA). The total RNA extraction reagent RNAiso Plus, a PrimeScript ${ }^{\mathrm{TM}}$ RT reagent kit and a SYBR ${ }^{\circledR}$ Green PCR kit were purchased from Takara Bio, Inc. (Shiga, Japan). Reagents for western blot analysis were purchased from Beyotime Institute of Biotechnology (Shanghai, China). Ox-LDL was obtained from Beijing Xiesheng Engineering Co., Ltd. (Beijing, China). LXR $\alpha$-short interfering (si)RNA was synthesized by Shanghai Genechem Co., Ltd (Shanghai, China). ABCA1, ABCG1 and LXR $\alpha$ specific antibodies were purchased from Wuhan Boster Biological Engineering Co., Ltd (Wuhan, China). All other chemicals were of the highest grade available from commercial sources.

Cell culture. Human THP-1 cells were cultured at a density of $1 \times 10^{6}$ cells/well in RPMI-1640 medium supplemented with $10 \% \mathrm{FBS}$ and $1 \%$ penicillin/streptomycin at $37^{\circ} \mathrm{C}$ in a $5 \% \mathrm{CO}_{2}$ incubator. THP-1 monocytes were treated with $160 \mathrm{nmol} / 1 \mathrm{PMA}$ for $24 \mathrm{~h}$ to facilitate the differentiation of monocytes into macrophages. Following PMA treatment, macrophages were incubated with $80 \mathrm{mg} / 1$ ox-LDL in serum-free RPMI-1640 medium containing 0.3\% BSA for $24 \mathrm{~h}$ in order to generate foam cells.

Measurement of cellular cholesterol efflux. Human macrophages were cultured as indicated. Macrophages were then labeled with $0.3 \mu \mathrm{Ci} / \mathrm{ml}\left[{ }^{3} \mathrm{H}\right]$ cholesterol in serum-free RPMI-1640 medium containing 0.2\% BSA for $24 \mathrm{~h}$. After $24 \mathrm{~h}$, cells were washed with phosphate-buffered saline (PBS) and incubated in serum-free RPMI-1640 medium containing $0.2 \% \mathrm{BSA}$ in the absence or presence of 10,50 or $100 \mathrm{ng} / \mathrm{ml} \mathrm{FGF} 21$ for $24 \mathrm{~h}$. Cells were then washed with PBS and incubated in RPMI-1640 medium containing 0.2\% BSA with $10 \mu \mathrm{g} / \mathrm{ml}$ apoA-I or $50 \mu \mathrm{g} / \mathrm{ml} \mathrm{HDL}$ for $24 \mathrm{~h}$. The efflux medium was obtained at the doses designated and centrifuged at $500 \mathrm{x}$ g for $3 \mathrm{~min}$. to remove any floating cells. Cell monolayers were washed twice with PBS and cellular lipids were extracted with isopropanol. Media and cell-associated $\left[{ }^{3} \mathrm{H}\right]$ cholesterol were then measured using a liquid scintillation counting method (21). Cholesterol efflux was expressed as the percentage of counts in the medium relative to the total count in the medium and cells combined.

Quantitative polymerase chain reaction ( $q P C R$ ). Total RNA was extracted using the RNAiso Plus reagent (Takara Bio, Inc., Shiga, Japan) in accordance with the manufacturer's instructions. The PCR primer sequences used were as follows: Forward: 5'-CTGGTT CTATGCCCGCT TGA-3' and reverse: 5'-TCTGCATTCCAC CTGACAGC-3' for ABCA1; forward: 5'-CTGCTGCCGCAT CTCACTG-3' and reverse: 5'-TCCCTTCTGCCTTCA TCCTTC-3' for ABCG1; forward: 5'-CTGTGCCTGACATTC CTCCT-3' and reverse: 5'-CATCCTGGCTTCCTCTCTGA-3' for LXR $\alpha$; and forward: 5'-GAGTCAACGGATTTGGTCGT-3' and reverse: 5'-TTGATTTTGGAGGGATCTCG-3' for GAPDH. qPCR was performed using SYBR ${ }^{\circledR}$ Premix Ex Taq ${ }^{\mathrm{TM}}$ II in a Bio-Rad LightCycler with an iQ3.1 Realtime PCR system (Bio-Rad, Hercules, CA, USA). GAPDH was used as an internal control. Quantitative measurements were analyzed using the $\Delta \Delta \mathrm{Ct}$ method.

Western blot analysis. Cells were washed twice with PBS and harvested in lysis buffer (10 mM HEPES, pH 7.9; $10 \mathrm{mM}$ $\mathrm{KCl}, 1.5 \mathrm{mM} \mathrm{MgCl} 2,0.5 \%$ Nonidet P-40, $1 \mu \mathrm{g} / \mathrm{ml}$ leupeptin, $10 \mu \mathrm{g} / \mathrm{ml}$ aprotinin and $1 \mathrm{mM}$ phenylmethylsulfonyl fluoride) for western blot analysis. Nuclei were pelleted at $5000 \mathrm{x} \mathrm{g}$ for $5 \mathrm{~min}$ at $4^{\circ} \mathrm{C}$ and the resulting supernatant was used as the cytosolic fraction. Nuclei were resuspended in lysis buffer, sheared for $15 \mathrm{sec}$ using a microprobe sonicator (Hangzhou Success Ultrasonic Equipment Co., Ltd., Hangzhou, China). and incubated on ice for $5 \mathrm{~min}$. Subsequent to centrifugation at $12,000 \mathrm{x} \mathrm{g}$ for $5 \mathrm{~min}$ at $4^{\circ} \mathrm{C}$, the supernatant was collected as nuclear extracts. Cellular lysates or nuclear protein extracts $(40 \mu \mathrm{g})$ were separated using 10\% SDS-PAGE and transferred onto Immobilon ${ }^{\circledR}-\mathrm{P}$ membranes (Millipore, Billerica, MA, USA). Membranes were blocked in 5\% skimmed milk in Tris-buffered saline with Tween-20 (0.1\% Tween-20, pH 7.4) and incubated with human antibodies against ABCA1, ABCG1 and LXR $\alpha$. Membranes were then incubated with horseradish peroxidase-conjugated goat anti-rabbit polyclonal antibody (Beijing Zhongshan Golden Bridge Biotechnology Co., Ltd., Beijing, China). GAPDH was used as an internal control. Proteins were visualized using an enhanced chemiluminescence detection system (Amersham International, Buckinghamshire, UK).

Transfection for $L X R \alpha$ silencing. siRNA specific to human LXR $\alpha$ and a nonsilencing control siRNA were synthesized by the Biology Engineering Corporation (Shanghai, China). Cells were transfected with each siRNA as described previously $(22,23)$. Annealed oligos for shRNA expression were cloned into the pSilencer ${ }^{\mathrm{TM}} 2.1-\mathrm{U} 6$ vector 


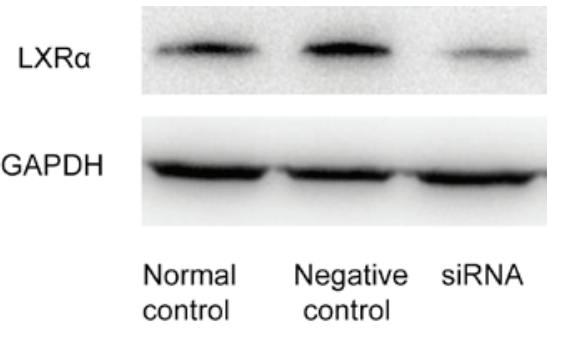

Figure 1. LXR $\alpha$ siRNA suppresses LXR $\alpha$ protein expression. THP-1 macrophage-derived foam cells were transfected with control or LXR $\alpha$ siRNA and incubated with $100 \mathrm{ng} / \mathrm{ml}$ FGF21 for $24 \mathrm{~h}$. Western blot analysis was performed using protein samples and anti-LXR $\alpha$ and -GAPDH antibodies. Data represent three experiments with different cell preparations. LXR $\alpha$, liver $\mathrm{X}$ receptor $\alpha$; siRNA, small interfering RNA.

A

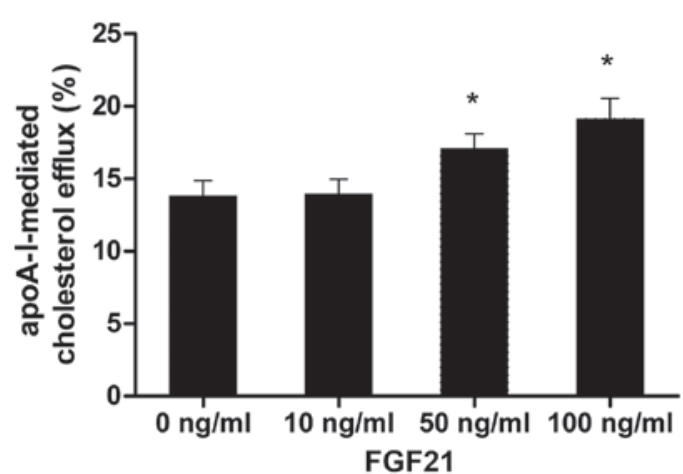

B

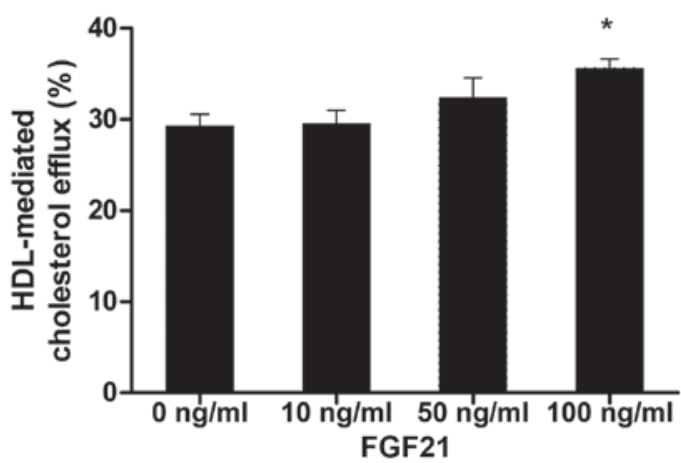

Figure 2.FGF21 enhances cholesterol efflux from THP-1 macrophage-derived foam cells. THP-1 macrophage-derived foam cells were incubated with various doses of FGF21 for $24 \mathrm{~h}$. Cellular apoA-I- and HDL-mediated cholesterol efflux was analyzed using a liquid scintillation counting method. All data are expressed as the mean \pm standard deviation from three independent experiments, each performed in triplicate. ${ }^{*} \mathrm{P}<0.05$ vs. the contro group. FGF21, fibroblast growth factor 21; apoA-I, apolipoprotein A1; HDL, high-density lipoprotein.

(Biology Engineering Corporation, Shanghai, China) linearized with BamHI and HindIII. The oligonucleotide sequences used to construct siRNA were as follows: forward 5'-ACTGAAGCGGCAAGAGGAGTTCAAGAGA CTCCTCTTGCCGCTTCAGTTTTTTT-3' and reverse 5'-AATTAAAAAAAACTGAAGCGGCAAGAGGAGTCTCT TGAACTCCTCTTGCCGCTTCAGTGGCC-3'. The products were transformed into competent Escherichia coli DH5 $\alpha$ cells (Beijing TransGen Biotech Co., Ltd., Beijing, China). and cultured on Luria-Bertani plates with $100 \mu \mathrm{g} / \mathrm{ml}$ ampicillin. Ampicillin-resistant colonies were selected using
A

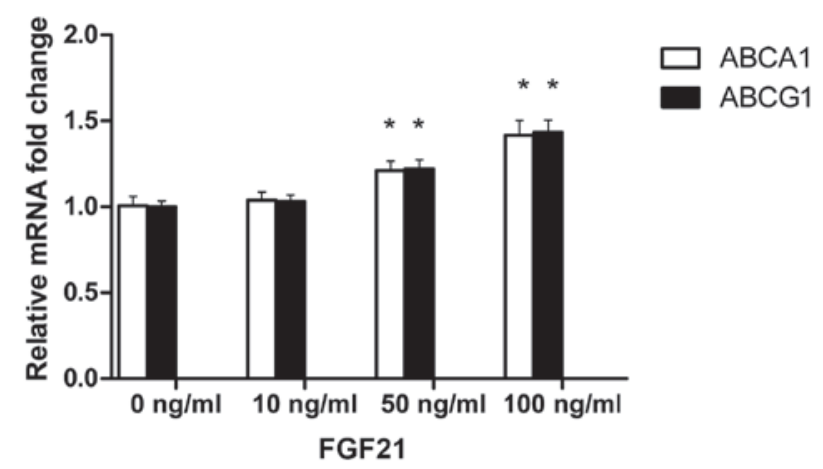

B

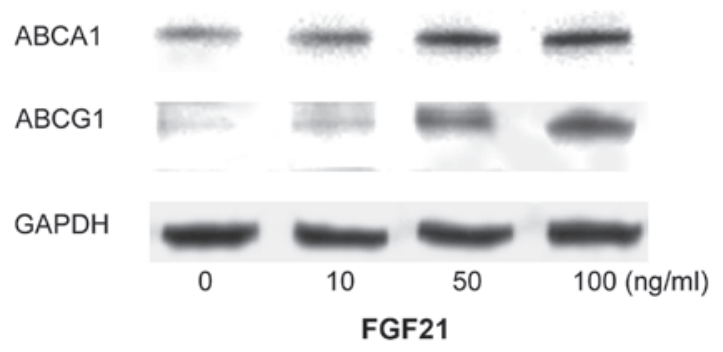

Figure 3. FGF21 upregulates the expression of ABCA1/G1 in THP-1 macrophage-derived foam cells. THP-1 macrophage-derived foam cells were incubated with various doses of FGF21 for 24 h. (A) ABCA1 and ABCG1 mRNA expression was measured using quantitative polymerase chain reaction analysis. (B) ABCA1 and ABCG1 protein expression was measured using western blot analysis. Data are expressed as the mean \pm standard deviation from three independent experiments, each performed in triplicate. ${ }^{*} \mathrm{P}<0.05$ vs. the control group. FGF21, fibroblast growth factor $21 ;$ ABC, ATP binding cassette.

restriction digestion and verified using DNA sequencing. For transfection with siRNA, foam cells were plated in 96-well plates at a density of $1 \times 10^{6}$ cells/well. After $24 \mathrm{~h}$, cells were transfected with LXR $\alpha$ siRNA in OptiMEM ${ }^{\circledR}$ with $5 \mu \mathrm{g} / \mathrm{ml}$ Lipofectamine 2000 (Invitrogen Life Technologies, Carlsbad, CA, USA). After $48 \mathrm{~h}$ of transfection, western blot analysis revealed that $\mathrm{LXR} \alpha$ siRNA suppressed the protein expression of LXR $\alpha$ by $80 \%$, compared with the cells transfected with the control siRNA (Fig. 1).

Statistical analysis. All experiments were performed at least three times. Data are presented as the mean \pm standard deviation. Results were analyzed by one-way analysis of variance and Student's t-tests, using SPSS 13.0 software (SPSS, Inc., Chicago, IL, USA). $\mathrm{P}<0.05$ was considered to indicate a statistically significant difference.

\section{Results}

FGF21 enhances apoA-I- and HDL-mediated cholesterol efflux from THP-1 macrophage-derived foam cells. The effect of FGF21 on cholesterol efflux in THP-1 macrophage-derived foam cells was analyzed using a liquid scintillation counter with apoA-I or HDL as a cholesterol acceptor. A dose course study was performed. Treatment with FGF21 at 50 and $100 \mathrm{ng} / \mathrm{ml}$ was found to enhance apoA-I-mediated cholesterol efflux compared with the control group $(\mathrm{P}<0.05)$, and 
A

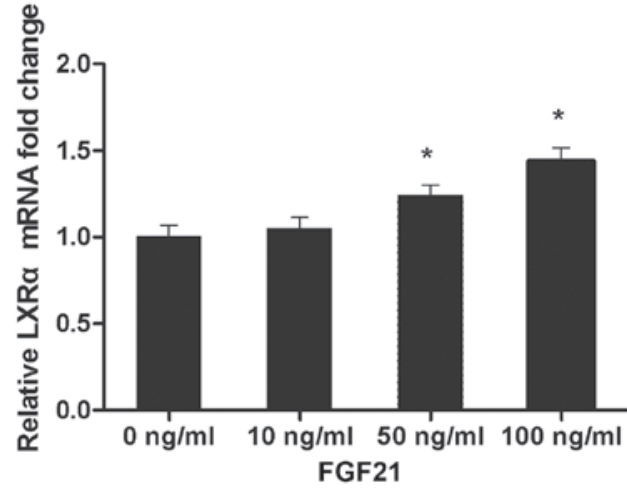

C

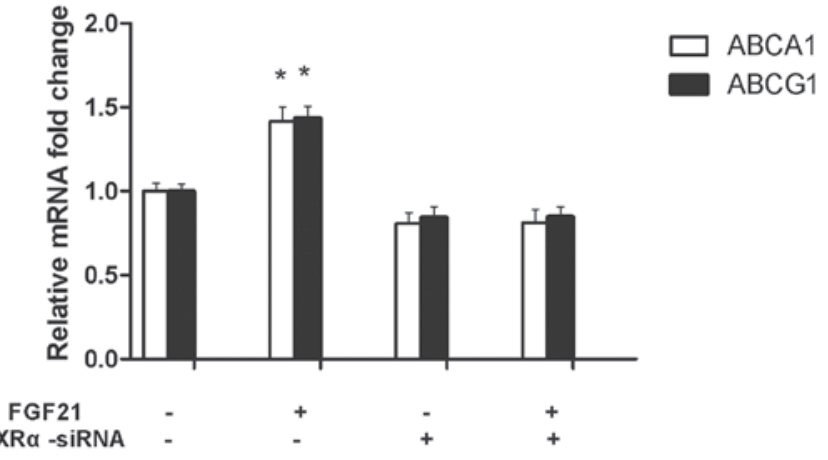

$\mathbf{E}$

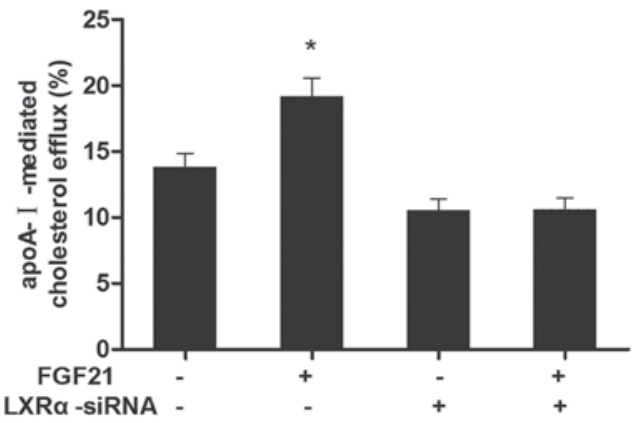

B

LXRa

GAPDH

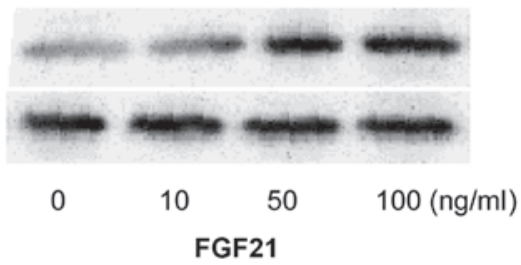

D

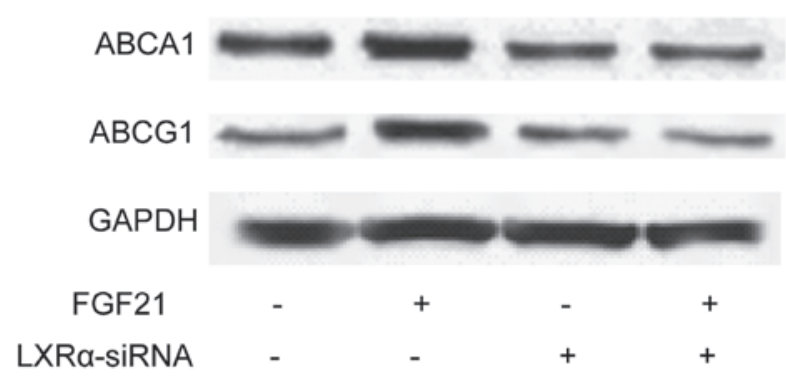

$\mathbf{F}$

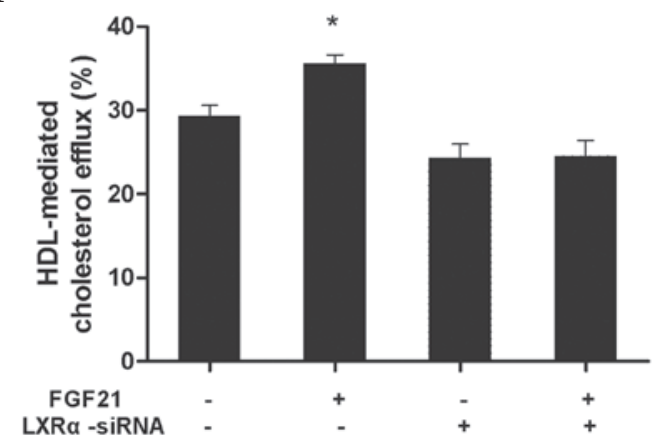

Figure 4. LXR $\alpha$ mediates the FGF21-induced upregulation of ABCA1/G1 in THP-1 macrophage-derived foam cells. (A and B) FGF21 increases the expression of LXR $\alpha$ at the mRNA and protein levels. THP-1 macrophage-derived foam cells were incubated with various doses of FGF21 for $24 \mathrm{~h}$. (A) LXR $\alpha$ mRNA expression was measured using qPCR. (B) LXR $\alpha$ protein expression was measured using western blot analysis. (C-F) THP-1 macrophage-derived foam cells were transfected with control or LXR $\alpha$ siRNA and incubated with $100 \mathrm{ng} / \mathrm{ml} \mathrm{FGF} 21$ for $24 \mathrm{~h}$. (C and D) ABCA1 and ABCG1 mRNA and protein expression were measured using qPCR and western blot analyses. (E and F) apoA-I- and HDL-mediated cholesterol efflux was analyzed using liquid scintillation counting. All data are presented as the mean \pm standard deviation from three independent experiments, each performed in triplicate. ${ }^{*} \mathrm{P}<0.05 \mathrm{vs}$. the control group. LXR $\alpha$, liver X receptor $\alpha$; siRNA, small interfering RNA; qPCR, quantitative polymerase chain reaction; FGF21, fibroblast growth factor 21; ABC, ATP binding cassette; HDL, high-density lipoprotein; apoA-I, apolipoprotein A1.

FGF21 at $100 \mathrm{ng} / \mathrm{ml}$ was found to enhance HDL-mediated cholesterol efflux compared with the control group $(\mathrm{P}<0.05)$.

FGF21 upregulates the expression of $A B C A 1$ and $A B C G 1$ in THP-1 macrophage-derived foam cells. ABCA1 and ABCG1 have been identified to have a key role in cholesterol efflux and foam cell formation in macrophages. In order to determine whether FGF21 enhances cholesterol efflux through modifying ABCA1 and ABCG1 expression, the expression of ABCA1 and ABCG1 was assessed using qPCR and western blot analyses in FGF21-treated THP-1 macrophage-derived foam cells. At
50 and $100 \mathrm{ng} / \mathrm{ml}, \mathrm{FGF} 21$ was observed to significantly upregulate the mRNA expression of ABCA1 and ABCG1 (Fig. 3A). Similar results were observed for ABCA1 and ABCG1 protein expression (Fig. 3B).

LXR $\alpha$ mediates the FGF21-induced upregulation of ABCA1 and ABCG1 in THP-1 macrophage-derived foam cells. It is well established that $\operatorname{LXR} \alpha$ activation induces the expression of ABCA1 and ABCG1. The following experiments were performed in order to examine the role of $\operatorname{LXR} \alpha$ in FGF21-treated macrophages. qPCR and western blot analyses 
were performed to assess whether FGF21 alters LXR $\alpha$ expression. FGF21 was found to induce an increase in $\mathrm{LXR} \alpha$ expression at the mRNA (Fig. 4A) and protein (Fig. 4B) levels. LXR $\alpha$ expression was then silenced using siRNA to examine the role of LXR $\alpha$ in the FGF21-induced upregulation of ABCA1 and ABCG1. The upregulation of ABCA1 and ABCG1 mRNA expression induced by FGF21 was observed to be attenuated in the LXR $\alpha$-siRNA-treated foam cells compared with those solely treated with FGF21 (Fig. 4C). Similar results were obtained in the upregulation of ABCA1 and ABCG1 protein expression (Fig. 4D). FGF21-induced apoA-I- and HDL-mediated cholesterol efflux was also attenuated in foam cells treated with LXR $\alpha$-siRNA compared with those solely treated with FGF21 (Fig. 4E and F). These findings suggest that the FGF21-induced activation of LXR $\alpha$ may be responsible for the effect of FGF21 on cholesterol efflux and ABCA1 and ABCG1 expression.

\section{Discussion}

To the best of our knowledge, the present study is the first study to demonstrate that macrophages are a target of FGF21, and preliminary data suggest that FGF21 may have a protective effect against atherosclerosis. FGF21 was found to enhance apoA-I- and HDL-mediated cholesterol efflux in THP-1 macrophage-derived foam cells. FGF21 was also observed to upregulate the mRNA and protein expression of ABCA1 and ABCG1. Furthermore, LXR $\alpha$ was found to be involved in facilitating these FGF21-induced effects.

A growing body of evidence has shown that FGF21 has numerous benefits on glucose and lipid metabolism and insulin sensitivity (13). Therefore, FGF21 may be beneficial for the treatment of metabolic diseases, including non-alcoholic fatty liver disease, type 2 diabetes and dyslipidemia, suggesting that FGF21 may have the potential to prevent the development of atherosclerosis. Thus, the present study aimed to investigate whether FGF21 has the capacity to reverse cholesterol transport, a process that is particularly important in atherosclerosis and the regression of atherosclerotic plaques.

Despite being a small fraction of the overall cholesterol efflux mediated by the RCT pathway, the efflux of cholesterol from macrophages has a significant inverse association with the risk of coronary artery disease, particularly atherosclerosis, independent of HDL cholesterol levels $(6,7)$. In the present study, FGF21-treated foam cells were found to exhibit a dose-dependent increase in apoA-I- and HDL-mediated cholesterol efflux.

Cholesterol efflux involves several important transporters and mechanisms (6). ABCA1 and ABCG1 are two of the most important proteins involved in mediating cholesterol efflux from macrophages to extracellular acceptors, including apoA-I and HDL. Therefore, ABCA1 and ABCG1 have important roles in the formation and metabolism of HDL (24). It is well established that extracellular apoA-I is a determinant of ABCA1-dependent cholesterol efflux. Moreover, HDL contributes to ABCG1-dependent cholesterol efflux (6). In the present study, FGF21 was found to enhance apoA-I- and HDL-mediated cholesterol efflux; thus, the effect of FGF21 on ABCA1 and ABCG1 was also investigated. In FGF21-treated cells, the increase in apoA-I- and HDL-mediated cholesterol efflux was observed to be consistent with an upregulation of ABCA1 and ABCG1 mRNA and protein expression. Therefore, FGF21-mediated upregulation of ABCA1 and ABCG1 may have anti-atherosclerotic effects, through enhancing cholesterol efflux.

Numerous studies have revealed that LXR $\alpha$ has a significant role in lipid metabolism and that increases in LXR $\alpha$ in lipid-loaded macrophages upregulate ABCA1 and ABCG1 $(9,12,22,23)$. Therefore, the present study investigated the effect of FGF21 on the expression of LXR $\alpha$. The FGF21-induced upregulation of ABCA1 and ABCG1 expression was concurrent with an increase in LXR $\alpha$ expression. LXR $\alpha$-siRNA was then used to determine the role of LXR $\alpha$ in the FGF21-induced upregulation of ABCA1 and ABCG1. Knockdown of LXR $\alpha$ using siRNA was found to attenuate the FGF21-mediated upregulation of ABCA1 and ABCG1. Furthermore, the increase in cholesterol efflux induced by FGF21 was attenuated with the LXR $\alpha$-siRNA. These results suggest that $\mathrm{LXR} \alpha$ has a key role in conferring the therapeutic benefits of FGF21 in improving lipid metabolism. Despite the unique pathway identified in the present study, the specific mechanism by which FGF21 affects cholesterol efflux requires further investigation.

The inverse correlation between plasma HDL levels and the risk of atherosclerosis has been extensively investigated $(25,26)$. However, a recent study suggests that analysis of HDL function may be more beneficial than an assessment of HDL plasma levels (27). Although HDL has numerous beneficial functions, the protective effect of HDL against atherosclerosis is largely attributed to its capacity to promote cholesterol efflux from macrophage foam cells (28). FGF21-treatment has been reported to increase HDL plasma levels in diabetic monkeys (20). Notably, the present study found that FGF21 promoted RCT through enhancing cholesterol efflux, which is the most important function of HDL. This suggests that FGF21 may have the potential to protect against atherosclerosis.

In conclusion, the present study demonstrated that FGF21 increases apoA-I- and HDL-mediated cholesterol efflux in ox-LDL-stimulated macrophage foam cells, potentially through LXR $\alpha$-dependent upregulation of ABCA1 and ABCG1. This suggests a direct association between FGF21 treatment and inhibition of atherosclerosis. While these findings support a promising role for FGF21 in cholesterol efflux, its regulation, function and clinical application require further investigation in order to establish its specific pathophysiological role in atherosclerosis.

\section{Acknowledgements}

The authors would like to thank the Chongqing Key Laboratory of Metabolism on Lipid and Glucose for providing the THP-1 cells, as well as Professor Qin Zhou for the advice and technical support. This study was supported by the Department of Cardiology, First Affiliated Hospital, Chongqing Medical University, China.

\section{References}

1. Lusis AJ: Atherosclerosis. Nature 407: 233-241, 2000. 
2. Maxfield FR and Tabas I: Role of cholesterol and lipid organization in disease. Nature 438: 612-621, 2005.

3. Rader DJ, Alexander ET, Weibel GL, Billheimer J and Rothblat GH: The role of reverse cholesterol transport in animals and humans and relationship to atherosclerosis. J Lipid Res 50 (Suppl): S189-194, 2009.

4. Rosenson RS, Brewer HB Jr, Chapman MJ, Fazio S, Hussain MM Kontush A, Krauss RM, Otvos JD, Remaley AT and Schaefer EJ: HDL measures, particle heterogeneity, proposed nomenclature, and relation to atherosclerotic cardiovascular events. Clin Chem 57: 392-410, 2011.

5. Lewis GF and Rader DJ: New insights into the regulation of HDL metabolism and reverse cholesterol transport. Circ Res 96: $1221-1232,2005$

6. Rosenson RS, Brewer HB Jr, Davidson WS, Fayad ZA, Fuster V, Goldstein J, Hellerstein M, Jiang XC, Phillips MC, Rader DJ, et al: Cholesterol efflux and atheroprotection: advancing the concept of reverse cholesterol transport. Circulation 125: 1905-1919, 2012

7. Khera AV, Cuchel M, de la Llera-Moya M, Rodrigues A, Burke MF, Jafri K, French BC, Phillips JA, Mucksavage ML, Wilensky RL, et al: Cholesterol efflux capacity, high-density lipoprotein function, and atherosclerosis. N Engl J Med 364: 127-135, 2011.

8. Yu XH, Fu YC, Zhang DW, Yin K and Tang CK: Foam cells in atherosclerosis. Clin Chim Acta 424: 245-252, 2013.

9. Hu YW, Wang Q, Ma X, Li XX, Liu XH, Xiao J, Liao DF, Xiang J and Tang CK: TGF-beta1 up-regulates expression of ABCA1, ABCG1 and SR-BI through liver $\mathrm{X}$ receptor alpha signaling pathway in THP-1 macrophage-derived foam cells. J Atheroscler Thromb 17: 493-502, 2010.

10. Ni ZL, Zhao SP and Wu Z: ABCG1 - a potential therapeutic target for atherosclerosis. Med Hypotheses 69: 214-217, 2007.

11. Zhao C and Dahlman-Wright K: Liver X receptor in cholesterol metabolism. J Endocrinol 204: 233-240, 2010.

12. Tang SL, Chen WJ, Yin K, Zhao GJ, Mo ZC, Lv YC, Ouyang XP, Yu XH, Kuang HJ, Jiang ZS, et al: PAPP-A negatively regulates ABCA1, ABCG1 and SR-B1 expression by inhibiting LXR $\alpha$ through the IGF-I-mediated signaling pathway. Atherosclerosis 222: 344-354, 2012.

13. Woo YC, Xu A, Wang Y and Lam KS: Fibroblast growth factor 21 as an emerging metabolic regulator: clinical perspectives. Clin Endocrinol (Oxf) 78: 489-496, 2013.

14. Kharitonenkov A, Shiyanova TL, Koester A, Ford AM, Micanovic R, Galbreath EJ, Sandusky GE, Hammond LJ, Moyers JS, Owens RA, et al: FGF-21 as a novel metabolic regulator. J Clin Invest 115: 1627-1635, 2005.

15. Wente W, Efanov AM, Brenner M, Kharitonenkov A, Köster A, Sandusky GE, Sewing S, Treinies I, Zitzer H and Gromada J: Fibroblast growth factor-21 improves pancreatic beta-cell function and survival by activation of extracellular signal-regulated kinase 1/2 and Akt signaling pathways. Diabetes 55: 2470-2478, 2006.
16. Xu J, Stanislaus S, Chinookoswong N, Lau YY, Hager T, Patel J, Ge H, Weiszmann J, Lu SC, Graham M, et al: Acute glucose-lowering and insulin-sensitizing action of FGF21 in insulin-resistant mouse models - association with liver and adipose tissue effects. Am J Physiol Endocrinol Metab 297: E1105-E1114, 2009.

17. Hotta Y, Nakamura H, Konishi M, Murata Y, Takagi H, Matsumura S, Inoue K, Fushiki T and Itoh N: Fibroblast growth factor 21 regulates lipolysis in white adipose tissue but is not required for ketogenesis and triglyceride clearance in liver. Endocrinology 150: 4625-4633, 2009.

18. Inagaki T, Lin VY, Goetz R, Mohammadi M, Mangelsdorf DJ and Kliewer SA: Inhibition of growth hormone signaling by the fasting-induced hormone FGF21. Cell Metab 8: 77-83, 2008.

19. Coskun T, Bina HA, Schneider MA, Dunbar JD, Hu CC, Chen Y, Moller DE and Kharitonenkov A: Fibroblast growth factor 21 corrects obesity in mice. Endocrinology 149: 6018-6027, 2008.

20. Kharitonenkov A, Wroblewski VJ, Koester A, Chen YF, Clutinger CK, Tigno XT, Hansen BC, Shanafelt AB and Etgen GJ: The metabolic state of diabetic monkeys is regulated by fibroblast growth factor-21. Endocrinology 148: 774-781, 2007.

21. Ma AZ,Zhang Q and Song ZY: TNFa alter cholesterol metabolism in human macrophages via PKC- $\theta$-dependent pathway. BMC Biochem 14: 20, 2013

22. Chen SG, Xiao J,Liu XH,Liu MM,MoZC, Yin K, Zhao GJ,Jiang J, Cui LB, Tan CZ, et al: Ibrolipim increases ABCA1/G1 expression by the LXR $\alpha$ signaling pathway in THP-1 macrophage-derived foam cells. Acta Pharmacol Sin 31: 1343-1349, 2010.

23. Yan JQ, Tan CZ, Wu JH, Zhang DC, Chen JL, Zeng BY, Jiang YP, Nie J, Liu W, Liu Q, et al: Neopterin negatively regulates expression of ABCA1 and ABCG1 by the LXR $\alpha$ signaling pathway in THP-1 macrophage-derived foam cells. Mol Cell Biochem 379: 123-131, 2013.

24. Jessup W, Gelissen IC, Gaus K and Kritharides L: Roles of ATP binding cassette transporters $\mathrm{A} 1$ and $\mathrm{G} 1$, scavenger receptor $\mathrm{BI}$ and membrane lipid domains in cholesterol export from macrophages. Curr Opin Lipidol 17: 247-257, 2006.

25. Sharrett AR, Ballantyne CM, Coady SA, Heiss G, Sorlie PD, Catellier D and Patsch W: Coronary heart disease prediction from lipoprotein cholesterol levels, triglycerides, lipoprotein(a), apolipoproteins A-I and B, and HDL density subfractions: The Atherosclerosis Risk in Communities (ARIC) Study. Circulation 104: 1108-1113, 2001

26. Gordon DJ and Rifkind BM: High-density lipoprotein - the clinical implications of recent studies. N Engl J Med 321: 1311-1316, 1989.

27. Otocka-Kmiecik A, Mikhailidis DP, Nicholls SJ, Davidson M, Rysz J and Banach M: Dysfunctional HDL: a novel important diagnostic and therapeutic target in cardiovascular disease? Prog Lipid Res 51: 314-324, 2012.

28. Meurs I, Van Eck M and Van Berkel TJ: High-density lipoprotein: key molecule in cholesterol efflux and the prevention of atherosclerosis. Curr Pharm Des 16: 1445-1467, 2010. 